\title{
Preliminary Study of Potential Bioimplant from Glycerol Plasticized Starch-Microcrystalline Cellulose Composite
}

\author{
Galih Rineksa1, Yudan Whulanza², Misri Gozan ${ }^{1,2, *}$ \\ ${ }^{1}$ Department of Chemical Engineering, Faculty of Engineering, Universitas Indonesia, Indonesia \\ ${ }^{2}$ Research Center for Biomedical Engineering, Universitas Indonesia, Indonesia
}

\begin{abstract}
Biodegradable and bio-based substitutes for conventional plastics are on the rise in these past decades. One of the applications of bioplastic is for biomedical implants or bioimplant. Starch was plasticized using glycerol at varying amounts $(40 \%$ and $60 \%$ of dry starch mass) to produce thermoplastic starch (TPS). A reinforcement filler of microcrystalline cellulose (MCC) was used to improve the mechanical properties. The MCC content in this study was also varied $(0 \%, 2 \%, 4 \%$, and $8 \% \mathrm{w} / \mathrm{w})$. This paper studies the mechanical properties of starch-MCC composites for their potential as bioimplant. The optimum glycerol and MCC contents from the results are $40 \%$ glycerol and $8 \%$ MCC with 2.97 MPa tensile strength and $7.20 \%$ strain at break. Thus, the sample has the potential application in bioimplant material for trabecular bone replacement, which has an average tensile strength of $2 \mathrm{MPa}$ and strains at a break of $2.5 \%$.
\end{abstract}

This is an open access article under the CC BY-SA license

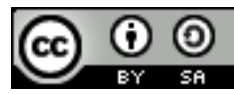

\section{INTRODUCTION}

Researchers have studied various biomasses to open up alternatives in plastic pollution reduction, including those from oil palm empty fruit bunches [1], sugarbeet [2], microalgae [3][4], silk [5] and starch [6]. One of the emerging applications of bioplastics is for a biomedical implant. Bioimplants are prostheses designed to help bring back physiological functions [7]. This definition implies that bioimplants should have decent levels of biocompatibility as well as decent mechanical properties. The biocompatibility with human bodies includes nontoxicity, biodegradability, and bioactivity/bio-inertness. Biodegradable polymers, especially polyesters, have been shown to serve this purpose relatively well and many types of research have been done on biopolyesters-based materials intended for bioimplant [8][9]. However, pure polyesters are hydrophobic and tend to have poor cell-adhesion [9][10]. In an attempt to solve this issue, this study investigated starch-based polymer, which is naturally hydrophilic, biocompatible, and biodegradable, to examine its potential to be used as a bioimplant.

Considering starch as a brittle material, the addition of plasticizer, heat, and shear are required to help starch lose its crystallinity and become thermoplastic. The chosen plasticizer should be polar and hydrophilic with a small molecular size [11]. These allow plasticizer

G. Rineksa et al., Preliminary Study of Potential Bioimplant from Glycerol Plasticized ... 
molecules to move around the granular starch, interrupting inter/intra-molecular hydrogen bonds of starch and replacing them by starch-plasticizer interaction, which quickly softens the structure $[11,12,13]$. The problem is that thermoplastic starch possesses poor mechanical properties such as tensile strength and Young's modulus. Moreover, pristine TPS absorbs water. It should be hindered because an increase in water content during storage or application could change glass transition temperature $\left(\mathrm{T}_{\mathrm{g}}\right)$ and crystallinity of the TPS (B-type crystallinity) [14]. The amount of water absorbed depends on the relative humidity at which the TPS is placed, the type of plasticizer, and temperature [14][15].

Studies show that MCC filler's presence helps various TPS improve its mechanical properties and reduce water uptake $[15,16,17]$. This study examines the bioimplant potential of starch-based polymer, which is naturally hydrophilic, biocompatible, and biodegradable. Experiments were carried out to observe the effect of concentration of microcrystalline cellulose (MCC) as a reinforcement filler and glycerol as a plasticizer on the mechanical properties of TPS.

\section{MATERIALS AND METHODS \\ Materials}

In this paper, the starch was obtained from Smart-Lab. Other materials include glycerol as a plasticizing agent of the starch to give the starch thermoplastic properties, distilled water as a solvent for mixing, and microcrystalline cellulose (MCC) as the reinforcement filler the thermoplastic starch-based composite. Glycerol and MCC were obtained from Merck.

\section{Synthesis of Thermoplastic Starch}

Starch was weighed, then plasticizing agent (glycerol) was added at varying mass (as an independent variable, $40 \%$ and $60 \%$ of dry starch mass). Water was also added as a solvent at ten times the mass of the starch. The mixture was stirred at $350 \mathrm{rpm}$ under a temperature of $90^{\circ} \mathrm{C}$ and atmospheric pressure using a magnetic stirrer set equipped with a hot plate. The stirring was carried out until the starch solution becomes gelatinized (thermoplastic starch).

\section{Addition of MCC}

The MCC - which depends on the desired MCC concentration - was made into a suspension in water (10-20 times the MCC mass) and added into the thermoplastic starch solution. The solution was then stirred again at $350 \mathrm{rpm}$ and $90^{\circ} \mathrm{C}$ for approximately half the time as the first stirring (thermoplastic starch making). The solution was poured into an evaporation dish and dried in an oven for 18 hours under $55^{\circ} \mathrm{C}$ temperature. The dried samples were then conditioned for 48 hours under room temperature and humidity $\left(25^{\circ} \mathrm{C}, 60 \%\right)$ before undergoing the next step, the mechanical testing.

\section{Mechanical Testing}

The samples were cut into regular rectangular pieces. The baseline sample was pure thermoplastic starch with no added reinforcement filler ( $0 \% \mathrm{MCC})$. The mechanical properties of the samples with added reinforcement filler $(2 \%, 4 \%$, and $8 \% \mathrm{MCC})$ were compared to the mechanical properties of the base sample (with no added reinforcement filler).

Each sample was cut into three pieces since there are three separate tests for each sample. Since the tensile strength - by definition - is the maximum stress that can be applied to the sample before it starts to break, the tensile strength (in MPa) is also equal to the maximum load (force) applied (in Newtons) before the sample starts to break divided by the cross-sectional area of the sample (in $\mathrm{mm}^{2}$ ). 
The first mechanical parameter, the tensile strength, was calculated according to the following equation (by inputting the maximum load):

$$
\sigma=\frac{F}{A}
$$

$\sigma=\operatorname{stress}(\mathrm{MPa})$

$\mathrm{F}=$ load (force, $\mathrm{N}$ )

$\mathrm{A}=$ cross-sectional area $\left(\mathrm{mm}^{2}\right)$

Another mechanical parameter to be tested is the elongation (strain) at the break, calculated according to the following equation:

$$
\varepsilon=\frac{\Delta L}{L_{0}}(* 100 \%)
$$

$\epsilon=$ strain

$\Delta L=$ elongation $(\mathrm{mm})$

$\mathrm{L}_{0}=$ initial sample length $(\mathrm{mm})$

The mechanical tests - both for tensile strength and strain at break - were carried out using Force Tester MCT-2150 (A\&D, Japan) mechanical testing device.

\section{RESULTS AND DISCUSSION}

\section{Tensile Strength}

The data for the tensile strength values for the samples with $40 \%$ and $60 \%$ added glycerol are shown in Figure 1 and Figure 2, respectively.

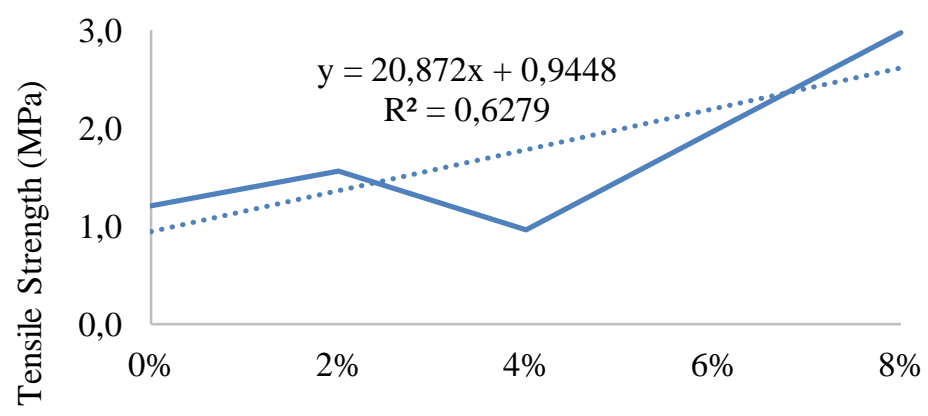

MCC Content

Figure 1. Tensile Strength Profile for 40\% Glycerol Samples

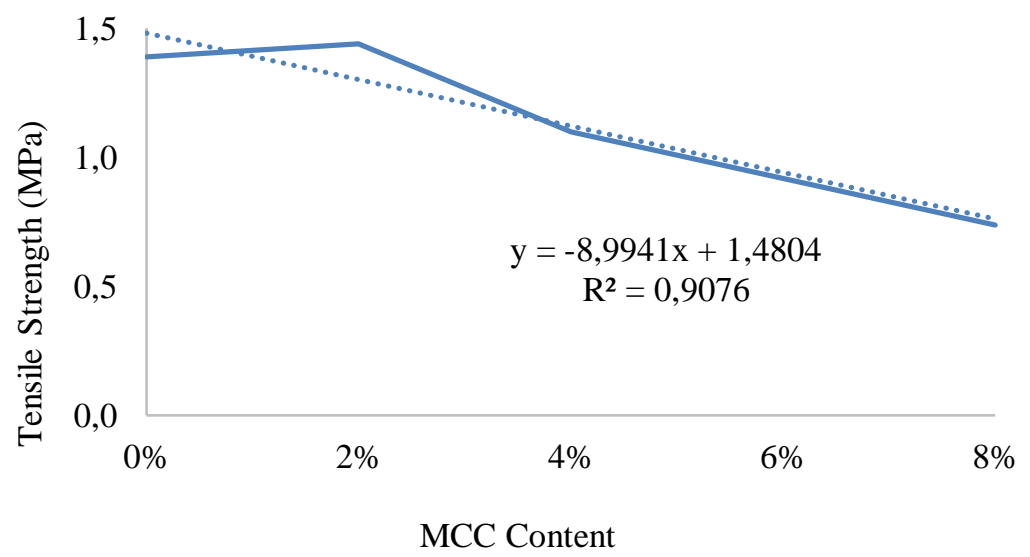

Figure 2. Tensile Strength Profile for $60 \%$ Glycerol Samples 
Figure 1 shows that the control sample ( $0 \%$ MCC content) with $40 \%$ glycerol has an average tensile strength of around 1.21 MPa. The trend is upwards. The addition of $8 \% \mathrm{MCC}$ increases the tensile strength significantly, by nearly $150 \%$ ( 2.5 -fold), than the sample without MCC, from 1.21 to $2.97 \mathrm{MPa}$.

As seen from Figure 2, the sample with no added MCC in the $60 \%$ glycerol samples has an average tensile strength of $1.39 \mathrm{MPa}$. Contrary to the results from the samples with $40 \%$ glycerol, the samples with $60 \%$ glycerol see a downward trend in tensile strength values as the MCC content increases. The sample with the most MCC content ( $8 \%$ added MCC) has roughly half $(0.74 \mathrm{MPa})$, the tensile strength of the sample with no added MCC.

\section{Strain at Break}

The value of strain or elongation at break is another mechanical property of the samples that are tested. The value of the strain at break can be traced in the strain profile by finding the value of strain when the stress (load) reaches the maximum point (i.e., when the stress begins to decrease). The device used for the strain at break calculation is the same as the one used for calculating the stress (tensile strength).

Data for strain at break values for the samples with $40 \%$ glycerol are shown in Figure 3. As seen from this figure, the strain at break values for the samples with $40 \%$ glycerol has a downward trend. It can be inferred from the strain at break data that by increasing the amount of MCC added to the sample, the value of the strain (elongation) at break decreases. Combined with the increasing value of the tensile strength, adding more MCC to the sample increases the Young modulus since the value of Young modulus is equal to stress divided by strain.

The data for strain at break values for samples with $60 \%$ added glycerol are shown in Figure 4. As seen from this figure, for the samples with $60 \%$ added glycerol, there are no noticeable trends (except for the slight increase in strain at break values from $2 \%$ to $8 \%$ MCC samples, but the $0 \%$ MCC sample has noticeably higher strain at break value compared to $2 \%$ ) in the strain at break profile. The common feature of the samples with $60 \%$ glycerol is the relatively high values of strain (elongation) at break (ranging from $12.8 \%$ to 18.6\%). In other words, the samples with $60 \%$ glycerol content are relatively flexible and extensible compared to the samples with $40 \%$ glycerol.



Figure 3. Strain at Break Profile for $40 \%$ Glycerol Samples 


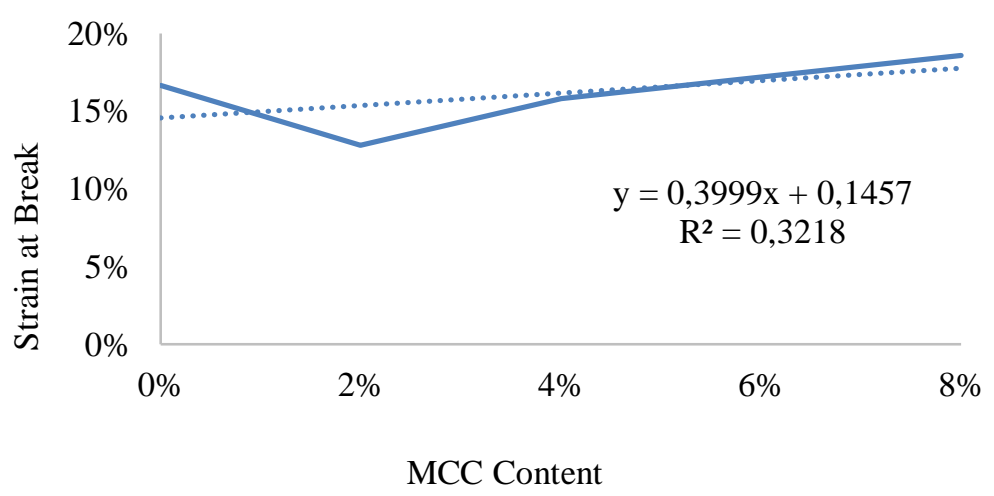

Figure 4. Strain at Break Profile for $60 \%$ Glycerol Samples

\section{Tensile Strength}

One of the factors affecting the tensile strength of TPS is the ratio between amylose and amylopectin of the native starch. High amylose content leads to higher tensile strength, whereas a high level of amylopectin lowers it [11]. The magnitude of the measured tensile strength in this study is more or less to the same degree as that observed by Ren et al. [18], who performed a study on potato-based TPS with varying plasticizer and halloysite nanotubes content.

As previously mentioned, the tensile strength for the samples with $40 \%$ glycerol increases as the amount of MCC increases. This increasing trend agrees with other studies on different TPS composites conducted by Wittaya [16]; Maulida et al. [17]; Ren et al. [18]; Jumaidin et al. [19]; and González et al. [20]. Tensile strength is largely determined by the intermolecular interaction between starch, glycerol, and MCC. The increasing tensile strength is most likely caused by the formation of a hydrogen bond network between MCC and the starch $[16,17,18]$. Cellulose and starch also have a similar chemical structure that might facilitate MCC integration in the starch matrix. This allows proper stress transfer between the starch matrix and the MCC, which is reflected in the improved tensile strength of the composites [19][20]. The errors (i.e., the low R-squared value) may stem from the fact that the drying is uneven - the moisture content throughout the sample could be uneven due to the shape of the container (evaporating dish) which resembles a bowl. Thus, the moisture-rich part accumulates in the center of the sample (the evaporating dish). As the moisture content also has a significant effect on the tensile strength of the samples, the errors thus occur.

For the samples with $60 \%$ glycerol content, the tensile strength slightly decreases as the amount of MCC increases. This downward trend is less pronounced (-8.99 gradient) than the upward trend of the samples with $40 \%$ glycerol content (+20.87 gradient), albeit with significantly higher accuracy (R-squared of $0.908 \mathrm{vs}$. 0.628 ). This might be due to the filler not being well distributed among the TPS containing 60\% glycerol. Thus, aggregates of MCC might be formed, which leads to phase discontinuation. The formation of aggregate seems more salient as MCC content increases in the composite, shown from the tensile strength that is further decreased. Such a trend was also observed by Fahrngruber et al. [21], using corn-based TPS reinforced with $1-5 \mathrm{wt} \%$ potato fiber. Wittaya [17] observed an opposite trend in ricestarch based TPS at MCC content of $0-35 \mathrm{wt} \%$, yet at MCC $>35 \%$, the tensile strength is also decreasing.

In general, the values of tensile strength for the samples with $60 \%$ glycerol are lower than that of $40 \%$ glycerol samples, especially the one with $8 \%$ MCC content (0.74 MPa vs. 2.97 $\mathrm{MPa}$; four times lower tensile strength). This is likely because plasticizers or glycerol in this case, despite giving flexibility to starch-based bioplastics, actually decrease the hardness 
[16][22] and weaken the intermolecular hydrogen bond between the matrix (starch) and the reinforcement filler (MCC) [23].

\section{Strain at Break}

The data given in Figure 3 showed that for samples with $40 \%$ glycerol content, the strain at break values see a downward trend as the MCC content increases. Fahrngruber et al. [19], Jumaidin et al. [20], and Gonzalez et al. [21] observed similar results. However, Ren et al. [18] had a contrary result, in which the strain increases with increasing filler content. All, except Fahrngruber et al. [21], obtained composites with good intermolecular force, as proven by increasing tensile strength with increasing filler content. Thus, the different observable trend might be due to the different filler size used. Comparing the result obtained in this study versus those mentioned beforehand, the composites whose filler's particle size is at least micrometric tend to have lower strain at break versus the neat TPS (without filler). On the other hand, composites with nanometric fillers tend to have higher elongation compare to the pristine TPS.

The factor contributing to the decrease in the strain at break is likely similar to that contributing to the increasing trend of tensile strength, i.e., the hydrogen bond between MCC and starch strengthens the starch-MCC composite and reduces the elasticity (the strain/elongation at break values). When the filler size is on the nanometric scale, the effect of hydrogen bond competes with the effect of plasticizer, in which the later tend to increase the strain at break.

For samples with $60 \%$ glycerol content, the strain values at break are higher than that of $40 \%$ glycerol content samples. A large amount of plasticizer added contributes a lot to the elasticity (elongation/strain at break values) since it increases the spacing between the molecules [23]. The lack of trend in the strain at break for samples with $60 \%$ glycerol might result from the contending effect between the higher glycerol content and the presence of aggregates in the composites at varying MCC concentration.

\section{Feasible Application as Bioimplant Material}

Overall, the sample with the highest tensile strength value is the sample with $40 \%$ glycerol and $8 \% \mathrm{MCC}$, with $2.97 \mathrm{MPa}$ - almost twice higher than the sample with the second-highest tensile strength value (40\% glycerol, $2 \% \mathrm{MCC}$ content, $1.56 \mathrm{MPa}$ ). According to a review [9], trabecular bone and cardiovascular tissues are examples of bodily tissues with an average tensile strength of less than $2.97 \mathrm{MPa}$ [24][25]. Therefore, the sample with $40 \%$ glycerol and $8 \%$ MCC meets the tensile strength standard requirement for trabecular bone and cardiovascular tissues. However, the sample with $40 \%$ glycerol and $8 \% \mathrm{MCC}$ also has relatively low strain at break $(7.20 \%)$. Since the bioimplant for cardiovascular tissues requires high elasticity standards [25], the sample has the potential as a scaffold to replace trabecular bone, which has an average strain at break of $2.5 \%$ [24]. The group of Reis has done extensive studies on the use of commercially available corn starch-based polymeric blend as a scaffold for bioimplants [26, $27,28,29,30,31]$. Thus, further study needs to be performed on the obtained composite to fulfill the intended purpose properly. Biocompatibility, scaffold processing method, the effect of body fluid on its properties, ability to guide cell proliferation, and degradation rates are the necessary properties that need to be further studied.

\section{CONCLUSIONS}

The presence of MCC in this study increases tensile strength. It decreases strain at break for samples with $40 \%$ glycerol due to hydrogen bonds forming between the starch matrix and MCC. For samples with $60 \%$ glycerol, there seems to be the formation of aggregates that 
compete with the effect of hydrogen bonds and plasticizer. This leads to a decrease in tensile strength with no specific trend for strain at break. The optimum sample obtained was $40 \%$ glycerol content and $8 \%$ MCC content, as the tensile strength is fairly high compared to other samples (2.97 MPa) (2.97 MPa tensile strength, 7.20\% strain at break). This sample meets the mechanical criteria for the bioimplant material intended to replace the trabecular bone (2 $\mathrm{MPa}$ tensile strength, $2.5 \%$ strain at break).

\section{ACKNOWLEDGEMENT}

The authors are grateful for the financial support of the present study provided by Publikasi Terindeks Internasional (PUTI) Doktor scheme for the budget year 2020. The scheme was granted by Universitas Indonesia (NKB-688/UN2.RST/HKP.05.00/2020).

\section{REFERENCES}

[1] Yustinah, N. Hidayat, R. Alamsyah, A. M. Roslan, H. Hermansyah, M. Gozan, "Production of polyhydroxybutyrate from oil palm empty fruit bunch (OPEFB) hydrolysates by Bacillus cereus suaeda B001," Biocatalysis and Agricultural Biotechnology, vol. 18, ID: 101019, 2019, doi: 10.1016/j.bcab.2019. 01.057

[2] V. L. Finkenstadt, L. Liu, and J. L. Willett, "Evaluation of poly (lactic acid) and sugarbeet pulp green composites," Journal of Polymer and the Environment, vol. 15, pp. 1-6, 2007, doi: 10.1007/s10924-0060038-z

[3] H. A. Sabathini, L. Windiani, D. Ismail, and M. Gozan, "Mechanical Physical Properties of Chlorella-PVA based Bioplastic with Ultrasonic Homogenizer," E3S Web of Web Conferences, 2018, vol. 67, no. 4, ID: 03046, doi: 10.1051/essconf/20186703046

[4] D. Ismail, C. Noviasari, L. Windiani, and M. Gozan, "Effect of compatibilizer addition in Spirulina platensis based bioplastic production," AIP Conference Proceedings, April 2019, vol. 1. ID: 030012, doi: 10.10631/1.5096716

[5] A. V. A. Sanjay, S. Suchart and P. Jyotishkumar, "Renewable and sustainable biobased materials: An assessment on biogibers, biofilms, biopolymers and biocomposites," Journal of Cleaner Production, vol. 258, pp. 120978, 2020

[6] A. Shafqat, A. Tahir, A. Mahmood, A. Pugazhendhi, “A review on envinronmental significance carbon foot prints of starch based bio-plastic: A substitute of conventional plastics," Biocatalysis and Agricultural Biotechnology, vol. 27, ID: 101540, 2020, doi: 10.1016/j.bcab.2020.101540

[7] M. Prakasam, J. Locs, K. Salma-Ancane, D. Loca, A. Largeteau, and L. Berzina-Cimdina, "Biodegradable Materials and Metallic Implants - A Review," Journal of Functional Biomaterials. 2017. Vol. 8, no. 4, pp. 44, 2017, doi: 10.3390/jfb8040044

[8] Rahmayetty, Y. Whulanza, Sukirno, S. F. Rahman, E. A. Suyono, M. Yohda and M. Gozan, "Use of Candida rugosa lipase as a biocatalyst for L-lactid ring-opening polymerization and polylactic acid production," Biocatalysis and Agricultural Biotechnology, vol. 16, pp. 683 - 691, 2018, doi: 10.1016/ j.bcab.2018.09.015

[9] I. Manavitehrani, A. Fathi, H. Badr, S. Daly, A. N. Shirazi and F. Dehghani, "Biomedical applications of biodegradable polyesters," Polymers, vol. 8, no. 1, pp. 20, 2016, doi: 10.3390/polym8010020

[10] I. Armentano, M. Dottori, E. Fortunati, S. Mattioli and J. M. Kenny, "Biodegradable polymer matrix nanocomposites for tissue engineering: a review," Polymer Degradation and Stability, vol. 95, no. 11, pp. 2126-2146, 2010, doi: 10.1016/j.polymdegradstab.2010.06.007

[11] Y. Zhang, C. Rempel and Q. Liu, "Thermoplastic starch processing and characteristics - a review," Critical Reviews in Food Science and Nutrition, vol. 54, no. 19, pp. 1353 - 1370, 2014, doi: 10.10180/10408398.2011.636156

[12] Y. Zhang and C. Rempel, "Retrogradation and antiplasticization of thermoplastic starch," In Thermoplastic elastomers, Prof. Adel El-Sonbati (Ed.), InTech, 2012, ISBN: 978-51-0346-2, available from http://www.intechopen.com/books/thermoplastic-elastomers/retrogradation-and-antiplasticizationofthermoplastic-starch

[13] A. M. Nafchi, M. Moradpour, M. Saeidi and A. A. Karim, Thermoplastic starches: properties, challenges, and prospects," Starch - Stärke, vol. 65, no. 1-2, pp. 61-72, 2013, doi: 10.1002/star.201200201 
[14] J. J. G. Van Soest, S. H. D. Hulleman, D. de Wit and J. F. G. Vliegenthart, "Changes in the mechanical properties of thermoplastic potato starch in relation to changes in B-type crystallinity", Carbohydrate Polymers, vol. 29, no. 3, pp. 225-232, 1996, doi: 10.1016/0144-8617(96)00011-2

[15] M. Rico, S. Rodriguez-Llamazares, L. Barral, R. Bouza and B. Montero, "Processing and Characterization of polyols plasticized-starch reinforced with microcrystalline cellulose," Carbohydrate Polymers, vol. 149, pp. 149, 83-93. 2016, doi: 10.1016/j.carbpol, 2016.04.087

[16] Maulida, M. Siagian and P. Tarigan, "Production of starch-based bioplastic from cassava peel reinforced with microcrystalline cellulose avicel ph101 using sorbitol as plasticizer," Journal of Physics, vol. 710, no. 1, ID: 12012, 2016, doi: 10.1088/1742-6596/710/1/012012

[17] T. Wittaya, "Microcomposites of rice starch film reinforced with microcrystalline cellulose from palm pressed fiber," International Food Research Journal, vol. 16, pp. 493-500, 2009

[18] J. Ren, K. M. Dang, E. Pollet and L. Avérous, "Preparation and characterization of thermoplastic potato starch/halloysite nano-biocomposites: effect of plasticizer nature and nanoclay content," Polymers, vol. 10, no. 8, pp. 808, 2018, doi: 10.3390/polym10080808

[19] R. Jumaidin, M.A.A. Khiruddin, Z.A.S. Saidi, M.S. Salit and R. A. Ilyas, "Effect of cogon grass fibre on the thermal, mechanical, and biodegradation properties of thermoplastic cassava starch biocomposite," International Journal of Biological Macromolecules, vol. 146, pp. 746 - 755, 2020, doi: 10.1016/j.ijbiomac.2019.11.011

[20] K. González, L. Iturriaga, A. González, A. Eceiza and N. Gabilondo,” Improving mechanical and barrier properties of thermoplastic starch and polysaccharide nanocrystals nanocomposites," European Polymer Journal, vol. 123, ID; 109415, 2020

[21] B. Fahrngruber, J. Eichelter, S. Erhausl, B. Seidl, R. Wimmer and N. Mundigler, "Potato-fiber modified thermoplastic starch: Effects of fiber content on material properties and compound characteristics," European Polymer Journal, vol. 111, pp. 170 - 177, 2019, doi: 10.1016/j.europolymj.2018.10.050

[22] M. G. A. Vieira, M. A. D. Silva, L. O. D. Santo and M. M. Beppu, "Natural-based plasticizers and biopolymer films: A review," European Polymer Journal, vol. 47, no. 3, pp. 254-263, 2011, doi: 10.1016/ j.europolymj.2010.12.011

[23] N. Cao, X. Yang and Y. Fu, "Effects of various plasticizers on mechanical and water vapor barrier properties of gelatin films," Food Hydrocolloids, vol. 23, no. 3, pp. 729-735, 2009, doi: 10.1016/j.foodhyd.2008.07.017

[24] L. Røhl, E. Larsen, F. Linde, A. Odgaard and J. Jørgensen, "Tensile and Compressive Properties of Cancellous Bone," Journal of Biomechanics, vol. 24, no. 12, pp. 1143-1149, 1991, doi: 10.1016/ 00219290(91)90006-9

[25] A. P. Ebrahimi, "Mechanical properties of normal and diseased cerebrovascular system," Journal of Vascular and Interventional Neurology, vol. 2, no. 2, pp. 155-162, 2009

[26] M. E. Gomes, J. S. Godinho, D. Tchalamov, A. M. Cunha and R. L., "Alternative tissue engineering scaffolds based on starch: processing methodologies, morphology, degradation, and mechanical properties," Materials Science and Engineering: C, vol. 20, no. 1-2. Pp. 19-26, 2002, doi: 10.1016/S09284931(02)00008-5

[27] H. S. Azevedo, F. M. Gama and R. L. Reis, "RL. In vitro assessment of the enzymatic degradation of several starch-based biomaterials," Biomacromolecules vol. 4, no. 6, pp. 1703 - 1712, 2003, doi: $10.1021 / \mathrm{bm} 0300397$

[28] I. B. Leonor, A. Ito, K. Onuma, N. Kanzaki and R. L. Reis, "In vitro bioactivity of starch thermoplastic/hydroxyapatite composite biomaterials: an in situ study using atomic force microscopy," Biomaterials, vol. 24, no. 4,m pp. 579-585, doi: 10.1016/S0142-9612(02)00371-X

[29] A. Martins, S. Chung, A. J. Pedro, S. A. Sousa, A. P. Marques, R. L. Reis and N. M. Neves, "Hierarchical starch-based fibrous scaffold for bone tissue engineering applications," Journal of Tissue Engineering and Regenerative Medicine, vol. 3, no. 1, pp. 37-42, 2009, doi: 10.1002/term.132

[30] I. Pashkuleva, P. M. Lopez-Perez, H. S. Azevedo and R. L. Reis, "Highly porous and interconnected starchbased scaffolds: Production, Characterization, and surface modification," Materials Science and Engineering: C, vol. 30, no. 7, pp. 981 - 989, 2010, doi: 10.1016/j.msec.2010.04.019

[31] J. F. Requicha, T. Moura, I. B. Leonor, T. Martins, F. Munoz, R. L. Reis, M. E. Gomes, C. A. Viegas, "Evaluation of a Starch-Based Double Layer Scaffold for Bone Regeneration in a Rat Model," Journal of Orthopaedic Research, vol. 32, no. 7, pp. 904-909, 2014, doi: 10.1002/jor.22609 